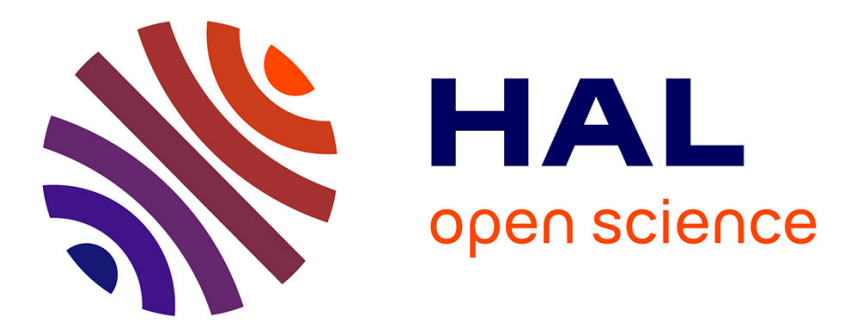

\title{
Misbehavior detection and efficient revocation within VANET
}

\author{
Hamssa Hasrouny, Abed Ellatif Samhat, Carole Bassil, Anis Laouiti
}

\section{To cite this version:}

Hamssa Hasrouny, Abed Ellatif Samhat, Carole Bassil, Anis Laouiti. Misbehavior detection and efficient revocation within VANET. Journal of information security and applications, 2019, 46, pp.193209. 10.1016/j.jisa.2019.03.001 . hal-02448040

\section{HAL Id: hal-02448040 \\ https://hal.science/hal-02448040}

Submitted on 25 Oct 2021

HAL is a multi-disciplinary open access archive for the deposit and dissemination of scientific research documents, whether they are published or not. The documents may come from teaching and research institutions in France or abroad, or from public or private research centers.
L'archive ouverte pluridisciplinaire HAL, est destinée au dépôt et à la diffusion de documents scientifiques de niveau recherche, publiés ou non, émanant des établissements d'enseignement et de recherche français ou étrangers, des laboratoires publics ou privés.

\section{다)(1) $(5$}

Distributed under a Creative Commons Attribution - NonCommercial| 4.0 International 


\title{
Microfluidics devices applied to radionuclides separation in acidic media for the nuclear fuel cycle
}

\section{Clarisse Mariet*, Axel Vansteene, Marion Losno, Julien Pellé, Jean-Philippe Jasmin, Anthony Bruchet, Gwendolyne Hellé}

Den—Service d'Etudes Analytiques et de Réactivité des Surfaces (SEARS), CEA, Université ParisSaclay, F-91191 Gif sur Yvette, France

clarisse.mariet@gmail.com

\begin{abstract}
Miniaturization of analytical devices provides new perspectives for safety improvement, intensification, and diversification of processes (reduction of matter shipment, reduction of stored materials, energy savings, reaction conditions that are inaccessible with macroscopic reactors...). This reduced scale satisfies most of the criteria of green analytical chemistry as well as the principle of minimization of hazards associated to radioactive samples, thanks to a major reduction of sample quantities, reactants, wastes, and analysis time, and to automation. An increasing number of specific microsystems or "labs-on-a-chip" have been developed with this ambition, particularly for radionuclides purification and separation steps, and for their analyses in complex and hard-to-handle samples. This article illustrates the development of microsystems for elemental separations in acidic media prior to isotopic or elemental measurements by mass spectrometry or a radiometric analysis method for nuclear-related activities, and underlines the main challenges to take up.
\end{abstract}

Keywords : solvent extraction ; extraction chromatography ; solid phase extraction ; monolith; functionalization

\section{Introduction}

The current nuclear reactor fuel consists of a mixture of oxides of uranium and plutonium or uranium oxide. After its stay in reactor, the fuel still contains a significant amount of valuable material which are interesting to recover. Moreover, the nuclear reactions that produced energy have also created other elements, fission products and minor actinides, which make the spent fuel highly radioactive. This is the reason for which the fuel is treated in order to separate material to recycle (uranium, plutonium) from other radioactive elements that constitute waste and condition waste in a safe and inert form. The hydrometallurgical recycling and the storage of the waste need conducting chemical 
analyses of the solutions after nuclear fuel dissolution [1-3]. The precise and accurate chemical analysis of nuclear spent fuel (determination of the concentration levels of Uranium, Plutonium and some Fission Products) represents a critical part of materials control and accountancy and plays an essential role in designing future nuclear fuels cycle, reprocessing cycle, after dissolution, and throughout the process for environmental regulatory reasons or non-proliferation monitoring.

To obtain low uncertainties using Thermo-Ionization Mass Spectrometry (TIMS) or Multi-Collection Inductively Coupled Plasma Mass Spectrometry (MC-ICPMS), mono-elemental samples are mandatory. Obtaining pure fractions of each radionuclides remains difficult because nuclear spent fuel samples exhibit an extreme chemical diversity stemming from several schemes of neutron capture, fissions or activation reactions that occur in reactors. This leads to the formation of the so-called transuranium radionuclides $(\mathrm{Np}, \mathrm{Pu}, \mathrm{Am}, \mathrm{Cm})$ as well as a wide variety of fission products constituted of Lanthanides (Nd, Sm, Eu, Gd), alkalines (Cs) and alkaline earth metals (Sr). Then, analysis of radionuclides is done according to operating protocols including the sequence of several separation/purification operations before performing the measurement by liquid scintillation, gamma spectrometry, X spectrometry or inductively coupled plasma mass spectrometry (ICP - MS) in order to remove interferences. Solid phase extraction (SPE) and liquid-liquid extraction (LLE) [4,5], performed in concentrated nitric or hydrochloric acid to form anionic and neutral complexes and stabilize oxidation degrees, pose a significant number of constraints specific to the sample (very irradiating which involves work in glove box, very corrosive), and the required precision. In addition, these separations are difficult to automate, involve the prolonged presence of an experimenter and generate large quantities of waste [6]. Methods dedicated to fast elementary or isotopic analyses, automated, consuming very little solvent, and targeting the desired compounds must be developed to acquire more numerous reliable data at a lower cost. The development of radiochemical separations in acidic media at the micrometric scale is part of the ALARA (As Low As Reasonably Achievable) approach for the reduction of waste and the handling of dangerous chemicals. The major interest of microsystems lies in their ability to integrate a series of operations on a small plate. Operations are faster and the same device brings together several identical processes in parallel. In addition, such a system takes in charge several steps without external intervention between the different stages. Thanks to micro-devices, the volumes of solvents and samples are reduced and operations are linked without human intervention, which limits the losses and contamination of samples.

If numerous microsystems have been developed and are already traded for medical diagnosis [7-9] or chemical synthesis $[10,11]$ since 2000 , few studies deal with very acidic samples like nuclear spent fuels or leach solutions issued from metallurgical processes. Unlike typical microfluidic devices that perform under about neutral $\mathrm{pH}$ conditions for biological and environmental applications, devices for radiochemical separations must be chemically compatible with strong mineral acids, and must also contribute negligibly to the trace element analytical blank. Reviews on the use of microfluidic devices 
have been published in several fields [12-18]. However, none have highlighted the use of microfluidic devices in very corrosive and complex media. Here, we have reviewed the state-of-the-art of microfluidic tools with a specific focus on the micro-devices used or designed for radionuclides separation in very acidic media.

\section{Liquid-liquid extraction of radionuclides in acidic media}

Very selective, liquid-liquid extraction is the preferred separation method of nuclear chemistry. Nuclear and pharmaceutical industries allowed its first industrial developments in the 1940s, then the oil and petrochemical industry in the 1955s-1965s. The real boom in the area of the hydrometallurgical allowing recovery of metals in various aqueous solutions (copper, uranium, gallium, rare earth, ...) happened in 1960 [19]. The solvent is made of thinner containing or not an extractant (organic molecule having an affinity for the element to be transferred). If the organic synthesis often uses the solvent extraction by spreading a species from one phase to the other by simple transfer [20, 21], in radiochemistry radioelement extraction is still implementing an extractant. In addition to the diffusion of the element there is a chemical reaction [22]. In this article, only liquid-liquid extraction has been considered.

Since its origins, to save natural resources and given the specific constraints related to radioactive and ionizing radiation, the nuclear industry prioritized raw material economy, recycling and minimization of the final waste, environmental footprint reduction and control of the risks of exposure for workers. This has led to the establishment of the recycling of the fuel, which allows to recover $96 \%$ materials and a minimization of the production of final waste. Now, continuous improvement of these processes is intended to improve their efficiency to decrease the cost, quantities of waste and improving safety around several axes: i) the development of new extractants for selective extraction of uranium ores in order to reduce the environmental impact of mining; ii) the development of new solvents for recycling of fuel which will be more robust, more compact and more efficient; iii) the miniaturization of systems, on the one hand, for the screening of new extractants, obtaining thermodynamic and kinetic data, the optimization of the parameters (temperature, $\mathrm{pH}$, concentrations) of extraction processes and, on the other hand for the analysis of effluents, waste, environmental samples...

Two types of miniaturized systems are identified in the literature regarding the liquid-liquid extraction of radionuclides. The so-called 'chaotic' reactors promote mixing of the phases $[23,24]$ and allow operation at counter-current of two immiscible phases [25]. By definition, the specific interfacial area of these systems is not known. Their dimensions are rather millimeter and flow rates are tens or even hundreds of $\mathrm{mL} \cdot \mathrm{h}^{-1}$ and they found application in the design of process engineering. 
Regarding lab on chips, they promote laminarity allowing accurate control of the specific interfacial area. Their dimensions are micrometer and flow rates are less than $10 \mathrm{~mL} \cdot \mathrm{h}^{-1}$, which explains their applications are analysis and R \& D. Liquid-liquid extraction microsystems provide many advantages such as large interfacial areas [26], short diffusion distance [26-28], high surface/volume ratio [29], process intensification [30] and possible integration of many operations stages on a single compact chip [31-33]. Solvent extraction in microchannels is a contact of two immiscible phases in a microchannel to promote the extraction of an element from one of the two phases towards the other. Only the case of the microsystems is treated in this article.

Two types of flows are implemented in microsystems: parallel flows and segmented flow (a phase is dispersed in the other) (Fig. 1).

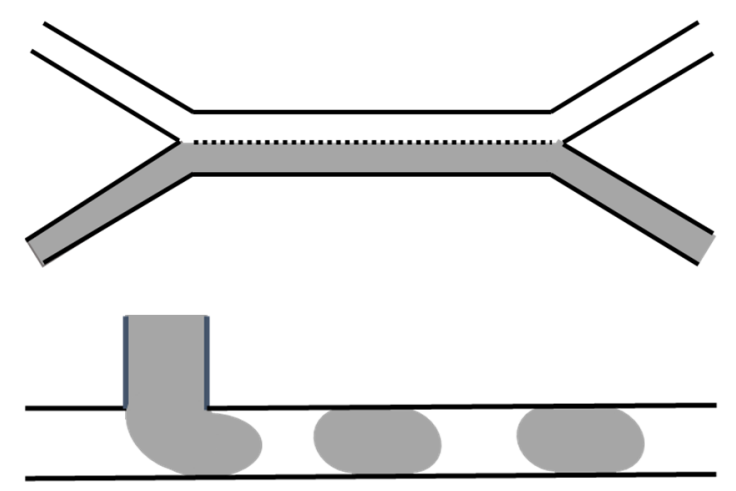

(a)

(b)

Fig. 1. (a) Parallel flows (b) segmented flow.

\subsection{Parallel flows}

Used for the first time in 2000 for the liquid-liquid micro-extraction ( $\mu$-LLE) of iron from an aqueous phase by an ion exchanger in the organic phase by Tokeshi et al. [34], many works have been reported on $\mu$-LLE of actinides, lanthanides or fission products in microsystem for analytical or industrial purposes. In most cases, $\mu$-LLE studies have been carried out in glass microsystems with Y junctions implementing parallel flows because such flow configuration allows deported analysis by collection of the two phases separately and the use of corrosive solvents (Fig. 2). 


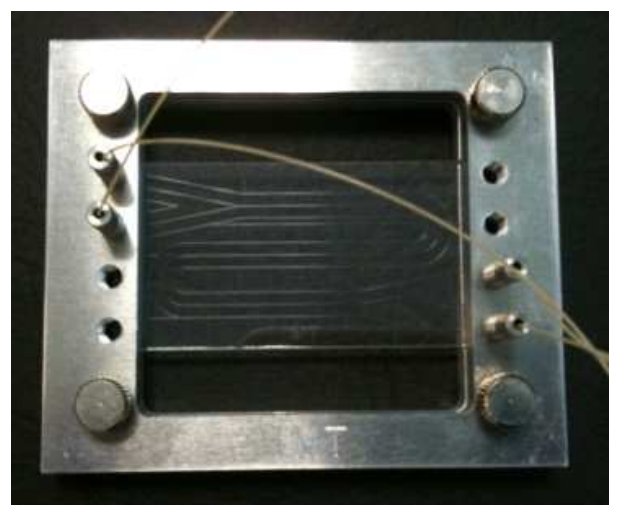

a

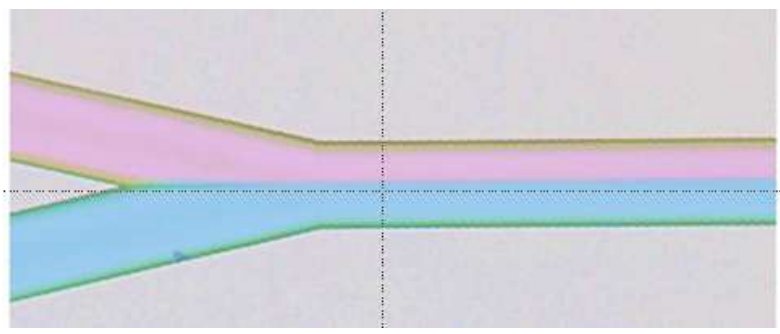

$\mathrm{b}$

Fig. 2. (a) Photography of a glass microsystem with Y-Y junctions purchased from $I_{M T}{ }^{R}$, the microchannel size: length $\mathrm{L}=8 \mathrm{~cm}$, width $\mathrm{w}=100 \mu \mathrm{m}$, depth $\mathrm{h}=40 \mu \mathrm{m}$. (b) Photography under the microscope of a biphasic system (organic / aqueous) laminar parallel flows in the microsystem.

From the point of view of radiochemical analysis, parallel flows are advantageous and liquid-liquid extraction coupling with stripping or detection techniques have become possible because the phases can be collected separately at the outlets of the microchannel. The specific interfacial area can reach $6000 \mathrm{~m}^{-1}[36]$, but cannot be changed for a given lab on a chip.

Originally, the purpose of the studies in parallel flows were first to show the feasibility of liquid-liquid extraction in microsystem and, second, to highlight the acceleration of the reaction related to the reduction of diffusion distances. This is the case of the studies on the solvent extraction of actinides $\mathrm{U}(\mathrm{VI}), \mathrm{Am}(\mathrm{III})$, and $\mathrm{Pu}(\mathrm{IV})$, respectively. Two-phase parallel flows $\mu$-LLE was performed in $\mathrm{Y}$ junction glass microsystems for the extraction of uranyl from nitric acid by tributylphosphate (TBP) [37-40]. As of 2005, Hotokezaka et al. [37] performed the extraction of $\mathrm{U}(\mathrm{VI})$ diluted in $\left[\mathrm{HNO}_{3}\right]=3$ mol. $\mathrm{L}^{-1}$ by the TBP (pure or diluted to $30 \%(\mathrm{v} / \mathrm{v})$ in the $\mathrm{n}$-dodecane). A yield of $93.8 \%$ was reached in 1 second with the organic phase at $30 \%(\mathrm{v} / \mathrm{v})$ of TBP, and only 0.7 second with pure TBP. The detection of the uranium in the aqueous phase was realized in-situ in the microchannel by thermal lens microscopy. Hellé et al. extracted U(VI) from hydrochloride acid with the anionic extractant tri-noctylmethylammonium (Aliquat 336®) diluted in a $n$-dodecane / 1-decanol mixture [31, 41, 42]. The only study on the extraction of Am(III) from nitric acid by the n-octyl phenyl N,N - diisobutyl carbamoylmethyl phosphine oxide (CMPO) diluted in $n$-dodecane was conducted by Ban et al. [43]. They also used a commercial glass made microsystem with Y-junction but with an unbalanced channel profile to ensure parallel phases flow. The equilibrium was achieved within 10 seconds of contact between the 2 phases. Recently, extraction of $\mathrm{Pu}(\mathrm{IV})$ was studied by Yamamoto et al. [44] between nitric acid and a $30 \%$ TBP in n-dodecane organic phase in stratified flows. These studies highlight that stratified flows solvent extractions in microsystems present the advantage to allow a precise control of the contact times of the two phases, especially short contact times, to lead to high speed and 
high performance without any mechanical stirring, mixing or shaking. Moreover, recent technological breakthroughs allow to work with automated microsystems which can be used in parallel processing to increase the throughput or in multiplexed processing of separation/purification steps coupled to a detection system [45, 46]. To take advantage of a combination of micro-unit operations and multiphase flow network, liquid-liquid extraction of the uranium(VI) in $\mathrm{HCl}$ media by Aliquat ${ }^{\circledR} 336$ coupling with stripping in the same microsystem was performed [31].

In the majority of the aforementioned studies, the detection was performed at the outlet of the microchannel by mass spectrometry on each phase recovered pure, so the interface was positioned at the center of the microchannel (Fig. 2-b). To set the interface position, the values of flow rates have to be adjusted considering viscosities values of the two immiscible phases [47]. During solvent extraction, the two phases viscosities are held constant because the extracted element is much less concentrated than the nitric acid or the extractant in the aqueous phase or in the organic phase, respectively. Then, when the radionuclide, is initially present at several tens of $\mathrm{g} . \mathrm{L}^{-1}$ in the aqueous phase, viscosities values are modified during the extraction process [35] and a change of the position of the interface between the two phases can be expected. This could involve a decrease of the quality of the separation at the outlet of the microsystem [36]. Hence, in 2017, Jasmin et al. [32] studied the extraction of $\mathrm{U}(\mathrm{VI})$ present at several tens g. $\mathrm{L}^{-1}$ from the nitric acid to the organic one ( $30 \% \mathrm{v} / \mathrm{v}$ TBP) and showed the influence of the modification of the phases' viscosities on the flow regime. For nuclear or hydrometallurgical applications, this problem has to be considered.

\subsection{Segmented flows}

In addition to stratified flows, phases can be put in contact by establishing segmented flow in $\mathrm{T}$ or flow-focusing junctions (Fig. 3). With segmented flow, specific interfacial area close to $11000 \mathrm{~m}^{-1}$ [35, 48] can be obtained. The continuous phase is the organic one if the walls of the microchannel are hydrophobic and the aqueous one if the walls are hydrophilic. On a practical level, the constraint in these flows lies in the need to separate the phases of lab-on-chip output to achieve linkages or measures on each of the phases if the detection does not have a measure in situ.

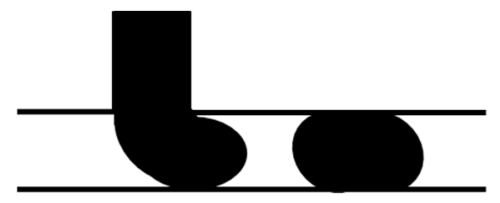

a

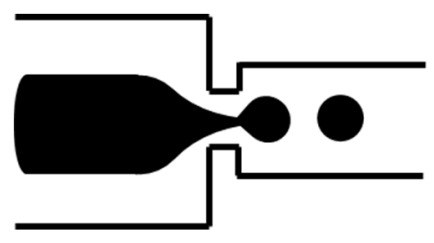

b

Fig. 3. Schematic of (a) a T-junction and (b) a flow-focusing junction used to establish segmented flows. In white the continuous phase and in black the segmented phase. 
The acquisition of kinetic data is of great interest in the screening of new extractants preformed to improve the future fuel reprocessing [49, 50]. Most often, the determination of the chemical reaction coefficients is performed with macroscopic tools which can be classified into two categories: i) tools characterized by a high dispersion of phases, but for which the interfacial area is unknown; ii) tools with controlled interfacial area for which the turbulence and dispersion are weak. Among them, a distinction can be made between tools in which the two immiscible phases are continuous (Lewis cell [51], Nitsch cell [52], rotating diffusion [53] and those in which one phase is dispersed and the other continuous (single drop technique) [54]). These tools have disadvantages. First, they necessitate a significant consumption of reagents that can be costly, the interfacial area is sometimes poorly controlled, and most often cannot be adjusted. The development of a fast and accurate new kinetic data acquisition methodology is an important issue. In order to be effective, the device used must have three key properties: (1) constant and well known specific interfacial area; (2) fast mixing of the two immiscible liquid phases, in order to operate in the kinetic regime, as opposed to the diffusion regime; (3) rapid and high-purity phase settling and separation [55].

In this context segmented flows in microsystems are new tools for kinetics studies [56]. Specific interfacial area can be modulated by changing flow conditions (droplet size can be adjusted [57-59]) and mass transfer is controlled mainly by the movements of internal forced convection to gout in movement. This impacts the mass transfer. Indeed, in microchannels, the velocity field inside the moving drop is not uniform and the renewal of the reagents at the interface is improved [48, 60-66]. Therefore, mass transfer is favored. This is the background for the recent studies of radionuclides extraction in segmented flows. For instance, segmented flows were implemented in Teflon capillaries for the extraction of uranyl from nitric media by Darekar et al. [67, 68] and Tsaoulidis and al. [65,66]. Extraction of U(VI) by TBP in segmented flow nitric media was studied by Tsaoulidis et al. [65, 66] who diluted TBP to $30 \%(\mathrm{v} / \mathrm{v}$ ) in ionic liquids, the organic phase being the continuous one. The influence of the residence time on the mass transfer for fixed flow rates was highlighted. Extraction of $\mathrm{U}(\mathrm{VI})$ increases with the time of residence. For an aqueous phase such as $\left[\mathrm{HNO}_{3}\right]=3$ mol. $\mathrm{L}^{-1}$, extraction reaches its equilibrium value of $91 \%$ in just 14 seconds (compared with 20 minutes in batch). Thereafter, Darekar, et al. [67, 68] studied the influence of the residence time of the drops on the transfer of material.

Nichols et al. [55] determined mass flow rates of 13 lanthanides and yttrium using a Teflon capillary to generate a segmented flow between an aqueous phase (diethylenetriaminepenta acetic acid and ammonium citrate) and an organic phase containing the extractant acid di-(2-ethylhexyl)phosphoric (HDEHP). A system that mimics the TRUEX (TRansUranium EXtraction) [69] liquid-liquid extraction process was studied in a flow-focusing junction by Nemer et al. [70]. The extraction of neodymium $\left(\mathrm{Nd}^{3+}\right)$ from aqueous droplets to dodecane using the complexant thenoyltrifluoroacetone 
(HTTA) and ligand TBP was chosen as a mass-transfer system model. Parameters including diffusion and distribution coefficients were obtained to better understand the contactor behavior.

Nirvik et al. [68] performed extraction and stripping in a combined microsystem. $\mu$-LLE experiments were carried out in a T-junction serpentine microchannel and a split-and-recombine microchannel with TBP-nitric acid system. Stripping experiments were carried out in the T-junction serpentine microchannel. The effects of residence time and the organic/aqueous ratio on overall volumetric masstransfer coefficients were discussed. Flow patterns in microchannels were observed to have more insight into experimental trends. For the same average velocity, the split-and-recombine microchannel was found to give higher overall volumetric mass-transfer coefficients. Overall volumetric masstransfer coefficients observed for the two microchannels were compared with overall volumetric masstransfer coefficients reported for conventional extractors.

The extraction of Eu(III) from nitric acid solutions was studied using anionic liquid solution ([CMPO] $=0.2 \mathrm{M}-[\mathrm{TBP}]=1.2 \mathrm{M})$ /1-butyl-3-methylimidazoliumbis[(trifluoromethyl)sulfonyl $]$ amide; $\left([\mathrm{C} 4 \mathrm{~min}]\left[\mathrm{NTf}_{2}\right]\right)$ as the extraction phase [71]. The investigations were carried out with the aqueous solution as the dispersed phase. The interfacial area in plug flow and the velocity profiles within the plugs, distribution and mass transfer coefficients were studied.

\subsection{Conclusion on solvent extraction in microsystems}

As shown with the study of the bibliography (Table 1), in most cases $\mu$-LLE developments have been carried out in glass microsystems with Y junctions implementing parallel flows because such flow configuration allows deported analysis by collection of the two phases separately [26, 76, 77]. However micro-droplets exhibit several properties that justify the use of these systems in research over classical macroscale reactors or miniaturized continuous flow microfluidic systems. Indeed, with segmented flow, recirculation of the compounds within the plugs of the dispersed phase and slugs of the continuous phase is responsible for a huge improvement in the global mass transfer [60]. The transport of the compounds within their respective phases is operated both by diffusion and advection. So, segmented flows may be used to retrieve or acquire kinetic data for various extracting molecules.

Table 1 : Synthesis of the literature review of extraction of nuclear systems studied in microsystems

\begin{tabular}{lccc}
\hline \multirow{2}{*}{ Extracted analyte } & Segmented flow \\
\cline { 3 - 3 } & Parallel flows & Organic continuous & Aqueous \\
& & phase & continuous phase \\
\hline
\end{tabular}


$\mathrm{U}(\mathrm{VI})$ in nitric acid extracted by TBP

$[37,67,68]$

[65-67]

[68]

U(VI) in hydrochloric acid extracted by

Aliquat 336

Am(III) in nitric acid extracted by

CMPO

$\mathrm{Pu}(\mathrm{IV})$ in nitric acid extracted by TBP

$\mathrm{Nd}$

$[48,72]$

[70]

Tm, Gd, Dy, Y par le PC-88A

$[33,73,74]$

Eu in nitric acid extracted by

DMDBTDMA

$[31,41,42]$

Eu in nitric acid extracted by CMPO

Lanthanides and Am stripping

$[55,75]$

\section{Solid phase extraction (SPE)}

Liquid chromatography for the separation of elements is currently used in radiochemistry for elemental and isotopic analyses protocols. The protocols on extraction chromatographic resins are widely implemented on radioactive samples for purified actinides or others elements like lanthanides [78-83]. Common methods for actinide matrix removal use chromatographic resin beds that are several milliliters in volume. The difficulty of the miniaturization of solid phase extraction in microsystem lies in the integration of the stationary phase in microchannel. Indeed, the stationary phase should allow the retention of the solutes, presenting a maximum exchange capacity and, often, be resistant to concentrated acids used in radiochemistry. Moreover, a sufficient resolution to obtained purified fraction of each radionuclide is needed. For radiochemical application in acidic media, two routes were considered: filling of the microchannels by particles [62] or a stationary phase synthesized in - situ $[6,84,85]$.

3.1 Particulate stationary phase in microchannel 
Two companies have addressed the manufacture of chromatographic microsystems as a simple scaledown technology transfer, from the usual chromatographic columns (inner diameter of $4.6 \mathrm{~mm}$ ) to microchannels of hundreds of microns or less, integrating particulate stationary phases. Agilent Technologies has developed a "top-down" approach by integrating the injection loop and the separation column into a microsystem in polyimide [86]. This device helped to significantly improve the robustness of the instrumentation, its ease of use and the reduction of the risk of leaks. In terms of performance, the integration of part of the injector in the microsystem minimizes external dispersion phenomena and improves separation [86, 87]. Eksigent society has adopted the same approach for its chip [88]. However, these two commercial chips found application in the field of biology.

To the best of our knowledge, to date, no commercial microsystem dedicated to the separation of metals or radionuclides has been developed and only one study implementing particulate stationary phase in microchannel was reported. Gao et al. [89] designed $100-\mu \mathrm{L}$ and $20-\mu \mathrm{L}$ solid-phase separation columns in microfluidic devices built in thermoplastic polyvinyl chloride (PVC, Fig. 4). The microcolumns, packed by centrifugation with specific resins, provide efficient actinide matrix removal from trace element impurities. Commercially-available anion exchange and chromatographic resins were chosen to separate traces impurities from concentrated thorium or uranium matrices in strong nitric acid solutions, while trace impurities passed through quantitatively for analysis by inductively coupled plasma - optical emission spectroscopy (ICP-OES). Actinides were subsequently recovered using dilute hydrochloric acid solution. The filling of the micro-colonnes was performed with the open system and phases particulate were held in place thanks to the presence of sintered at both ends of microcolonnes. Flow rates ranged from 20 to $100 \mu \mathrm{L} \cdot \mathrm{min}^{-1}$.

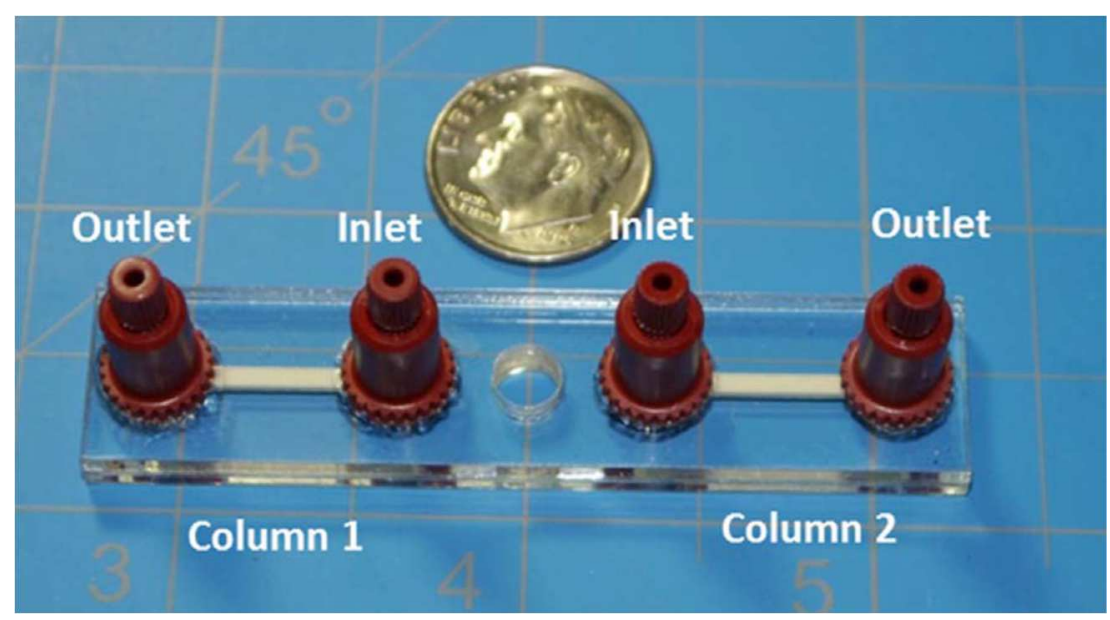

Fig. 4. Assembled 20- $\mu \mathrm{L}$ solid-phase extraction microfluidic device, filled with AG MP-1 resin (column 1) and UTEVA resin (column 2). Scale is illustrated using a US dime coin (17.9 mm diameter) [89]. 
3.2 Monolithic stationary phase synthesized in-situ in microchannel

Monolithic stationary phases in chromatography and electrochromatography emerged in the early 1990s [90, 91]. These materials gained popularity because they are formed from a single piece of porous material that includes large flow through pores enabling separations at high flow rates achieved at low back pressures. Organic monoliths can be easily prepared within the confines of a microchannel (mold) by photo-initiated polymerization of a mixture of monomers (functional and crosslinker), porogenic solvents, and a free radical initiator. Organic monoliths combine a good mechanical resistance by covalent anchored to the walls of the microchannels, good control of porosity and permeability, and wide possibilities of chemical functions. Reviews [91-94] demonstrated that organic polymer-based monoliths for off-line SPE can be prepared in formats including the conventional syringe cartridges, pipette tips, stir bars, and spin columns. For on-line SPE, however, the in-tube or microchip formats are mandatory, and include nuts and ferrules for fitting the column to the analyzers and flow-through detectors. Then, monolithic columns for extraction of metal ions from environmental water and biological matrices (human hair, urine, and serum) were prepared by functionalizing the stationary phase with complexing functionalities [95].

The strong acidity of the mobile phases used in radiochemistry leads to the use of organic monoliths for their chemical resistance.

Inspired from the study of Lafleur et al. [96] who have elaborated a monolithic microcolumn inserted into a centrifuge microsystem for the separation and analysis of $\mathrm{V}, \mathrm{Pb}, \mathrm{Cu}$ and $\mathrm{Co}$ in water to drink, Bruchet et al. [6] developed an original design of microfluidic platform integrating four rectangular microchips made of thermoplastic (cyclo olefin copolymer COC). The microchips, dedicated to anionexchange chromatographic separations, integrated a localized monolithic stationary phase as well as injection and collection reservoirs (Fig. 5). For a simplified simulated nuclear spent fuel sample composed of non-radioactive isotopes of $\mathrm{Eu}$ and $\mathrm{U}$ in usual proportion for Uranium Oxide nuclear spent fuel, analytical results were consistent with the conventional procedure (extraction yield for Europium of about $97 \%$ ). The use of the centrifugal microfluidic platform allowed to reduce the volume of liquid needed by a factor 250 . Thanks to their unique "easy-to-use" features, centrifugal microfluidic platforms are potential successful candidates for the downscaling of chromatographic separation of radioactive samples (automation, multiplexing, easy integration in glove-boxes environment and low cost of maintenance). A quaternary ammonium was covalently bound to the monolith thanks a thermal reaction. However, the functionalization was not robust in nitric acid media and the functionalization procedure was suitable only for the grafting of tertiary or secondary amines. 


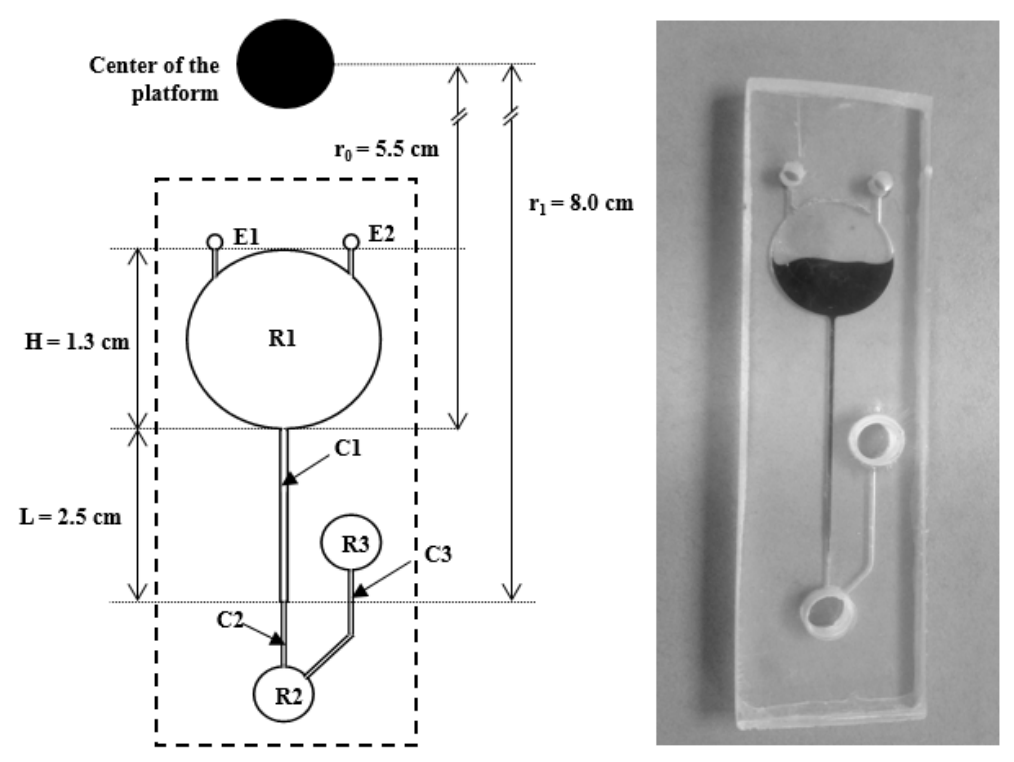

Fig. 5. Design of the microchips: $\mathrm{C} 1$ ion-exchange column, $\mathrm{C} 2$ restriction channel, $\mathrm{C} 3$ vent channel, $\mathrm{R} 1$ injection reservoir, R2 collection reservoir and chromatographic connection, R3 vent and chromatographic connection, E1 entry port and E2 vent port of the injection reservoir. The centrifugal platform is presented in [6].

To take advantage of the versatility and robustness in nitric media of chromatographic microsystems filled with a stationary particle phase while having the quality of filling of microsystems with a monolithic stationary phase, Losno et al. [84, 85] developed a new porous poly(ethylene glycol methacrylate - co-allyl methacrylate) monolithic microcolumn. A new way of functionalization based on impregnation with extractants customized for radionuclides separation in nitric acid media was devised in a simple microsystem $\mathrm{P} 1$ and in a centrifugal microsystem. The versatility of the functionalization was demonstrated by the impregnation of TBP, CMPO and TBP mixture or diamylamyl phosphonate (DAAP). Distribution coefficients were determined in microsystems for Eu, Th, U, Pu in nitric acid from 0 to 8 mol.L ${ }^{-1}$.

The separation of Eu, Th and $\mathrm{U}$ was performed in the simple microsystem functionalized with TBP with only $30 \mu \mathrm{L}$ of reagents compared to $\mathrm{mL}$ used in classical SPE with flow rates set at $2 \mu \mathrm{L} \mathrm{min}{ }^{-1}$. Compared to the protocol carried out for classic SPE [97], there is a significant reduction in volumes handled (Table 2). The procedures of Gao et al. [89] is faster (about 30 minutes) than the one made on TBP impregnated monolith, but possible parallelization of separation in centrifugal microsystem allows to compensate for this difference.

Table 2 : Performance comparison of different SPE systems of radionuclides in acidic media

\begin{tabular}{lllllll} 
Separation & Separative & Column & Sample & Time & Media & Reference \\
\hline
\end{tabular}




\begin{tabular}{|c|c|c|c|c|c|c|}
\hline & column & $\begin{array}{c}\text { volume } \\
(\mu L)\end{array}$ & $\begin{array}{c}\text { volume } \\
(\mu L)\end{array}$ & (min) & & \\
\hline $\begin{array}{c}\mathrm{U} / \mathrm{Pu} / \mathrm{Am}, \mathrm{Eu}, \\
\mathrm{Ce}\end{array}$ & $\begin{array}{l}\text { Commercial column } \\
\text { TBP/CMPO }\end{array}$ & 2000 & 2500 & 90 & $\begin{array}{c}\mathrm{HNO}_{3}, \mathrm{HCl} \text { and } \\
\text { oxalic acid }\end{array}$ & [97] \\
\hline $\mathrm{Eu} / \mathrm{Th}, \mathrm{U}$ & $\begin{array}{c}\text { Microsystem P1 } \\
\text { TBP }\end{array}$ & 36 & 72 & 256 & $\mathrm{HNO}_{3}$ & [85] \\
\hline $\mathrm{Eu} / \mathrm{Th}, \mathrm{U}$ & $\begin{array}{c}\text { Centrifugal } \\
\text { microsystem TBP }\end{array}$ & 2.75 & 5.5 & 90 & $\mathrm{HNO}_{3}$ & [85] \\
\hline $\begin{array}{l}\mathrm{Pu} / \text { transition } \\
\text { metals, non } \\
\text { metals }\end{array}$ & $\begin{array}{c}\text { AG-MP1 et } \\
\text { UTEVA }^{\mathrm{TM}} \\
\text { Particulate stationary } \\
\text { phase in } \\
\text { microchannel }\end{array}$ & 100 & 200 & 25 & $\begin{array}{c}\mathrm{HNO}_{3} \\
\text { puis } \mathrm{HCl}\end{array}$ & [89] \\
\hline $\begin{array}{l}\mathrm{U} / \text { transition } \\
\text { metals, non } \\
\text { metals }\end{array}$ & $\begin{array}{c}\text { UTEVA }^{\mathrm{TM}} \\
\text { Particulate stationary } \\
\text { phase in } \\
\text { microchannel }\end{array}$ & 20 & 20 & 28 & $\begin{array}{c}\mathrm{HNO}_{3} \\
\text { puis } \mathrm{HCl}\end{array}$ & [89] \\
\hline $\mathrm{U} / \mathrm{Eu}$ & $\begin{array}{c}\text { Anionic exchanger } \\
\text { centrifugal } \\
\text { microsystem } \\
\end{array}$ & 2.5 & 5 & 65 & $\mathrm{HCl}$ & [6] \\
\hline
\end{tabular}

Compared to the classic SPE, a microsystem of extraction chromatographic incorporating a monolithic stationary phase dimensioned based on the detection limit of the measurement technique allows to make separations with volumes samples less than $100 \mu \mathrm{L}$ and at flow rates lower than $100 \mu \mathrm{L} . \mathrm{min}^{-1}$. Thanks to this tool, much less effluent will be generated by analysis that demand continually believes and the cost of waste management in nuclear laboratories will be reduced.

\section{Conclusion}

In 2011, George M. Whitesides noted microfluidics, and the concept of the lab-on-a-chip, have had a spectacularly successful 15-year run of science and technology [98]. He asked "what comes next?" Henceforth, this review is indicative of the rise of the development of lab on chips dedicated to radiochemistry. In the nuclear field, chemical and physico-chemical analysis and screening of new extractant now consider environmental issues in the development of a technique or a method of analysis. At every stage of an analytical process, the questions focus on:

- the reduction of volumes of reagents, solvents and samples;

- the reduction of waste production;

- the reduction of the consumption of energy, water, gas...

- the increase of speed and accuracy of the analytical response.

To meet current and future needs, the preferred development areas relate to:

i) the implementation of parallelizable and automatized sample preparation methods. Microfluidic tools already significantly reduce analytical effluent generated by the methods currently used in 
laboratories. However, their parallelism and their automation must still be subject to developments requiring the collaboration of chemists, control engineers, programmers.

(iii) the development of MicroTAS (miniaturized total analytical system). In radiochemistry, developed microsystems are coupled to spectrometers of laboratories for elemental or isotopic analyses. Now, the effort should focus on integration of the measure directly in the lab on a chip. It will lead to a drastic decrease of the volumes of samples and reagents.

\section{References}

[1] L.L. Burger, E.D. Mc Clanahan, Gamma Radiolysis. Tributyl phosphate and its diluent systems, Ind. Eng. Chem. 50(2) (1958) 153-156.

[2] J.G. Burr, The radiolysis of tributyl phosphate, Radiat. Res. 8(3) (1958) 214-221.

[3] W.W. Schulz, J.D. Navratil, Science and technology of tributyl phosphate CRC Press, USA, 1984(pp.)

[4] R.W. Durham and R. Mills, The absorption of plutonium by anion resins, Chalk River, Ontario, Atomic Energy of Canada Limited report 1399, 1953 (pp.)

[5] J.D. Navratil, Ion exchange technology in spent fuel reprocessing, J. Nuc. Sci. Tech. 26(8) (1989) 735-743.

[6] A. Bruchet, V. Taniga, S. Descroix, L. Malaquin, F. Goutelard, C. Mariet, Centrifugal microfluidic platform for radiochemistry: potentialities for the chemical analysis of nuclear spent fuels, Talanta 116 (2013) 488-494.

[7] K. Arshak, E. Jafer, G. Lyons, D. Morris, O. Korostynska, A review of low-power wireless sensor microsystems for biomedical capsule diagnosis, Microelectron. Int. 21(3) ((2004) 8-19.

[8] S. Mouradian, Lab-on-a-chip: applications in proteomics, Curr. Opinion in Chem. Biol., 6(1) (2002), 51-56.

[9] A. Ríos, M. Zougagh, M. Avila, Miniaturization through lab-on-a-chip: Utopia or reality for routine laboratories? A review, Anal. Chim. Acta 740 (2012) 1-11.

[10] P. Watts and S. J. Haswell, The application of micro reactors for organic synthesis, Chem. Soc. Rev. 34 (2005) 235-246.

[11] B.P. Mason, K.E. Price, J.L. Steinbacher, A.R. Bogdan, D. T. Mc Quade, Greener approaches to organic synthesis using microreactor technology, Chem. Rev. 107(6) (2007) 2300-2318. 
[12] D. Mark, S. Haeberle, G. Roth, F. von Stetten, R. Zengerle, Microfluidic lab-on-a-chip platforms: requirements, characteristics and applications, Chem Soc Rev 39 (2010) 1153-1182.

[13] T.M. Squires and S.R. Quake, Microfluidics: fluid physics at the nanoliter scale, Rev. Mod. Phys. 77(2005) 977-1026.

[14] J. Atencia and D.J. Beebe, Controlled microfluidic interfaces. Nature 437 (2004) 648-655.

[15] P. Gravesen, J. Branebjerg and O.S. Jensen, Microfluidics - a review, J. Micromechan. Microeng. 3(1993) 168-182.

[16] A. Abou-Hassan, O. Sandre, V. Cabuil, Microfluidics in inorganic chemistry. Angew Chem 49 (2010) 6268-6286.

[17] D.R. Reyes, D. Iossifidis, P.A. Auroux, A. Manz, Micro total analysis systems. 1. Introduction, theory and technology. Anal. Chem. 74 (2002) 2623-2636.

[18] D. Ciceri, J.M. Perera, G.W. Stevens, The use of microfluidic devices in solvent extraction, J. Chem. Technol. Biotechnol. 89 (2014) 771-786.

[19] G. Cote, Extraction liquide-liquide - Présentation générale. Techniques de l'ingénieur, 1998. $\mathrm{J} 2760$.

[20] J. G. Kralj, H.R. Sahoo, K.F. Jensen, Integrated continuous microfluidic liquid-liquid extraction Lab Chip 7 (2007) 256-263.

[21] Y. Zhao, G. Chen, Q. Yuan, Liquid-liquid two-phase mass transfer in the T-junction microchannels, AIChE Journal 53(12) (2007) 3042-3053.

[22] G. Cote, Extraction liquide-liquide - Bases physico-chimiques des procédés, Techniques de l'ingénieur J2761.

[23] T. Xie, M. Chen, C. Xu, J. Chen, Two-stage feedback miniextractor with high-throughput via selective dimension scale-out. Ind. Eng. Chem. Res., 56(41) (2017) 11948-11957.

[24] C. Xu, and Y. Dai, High-throughput production of droplets using mini hydrodynamic focusing devices with recirculation. Ind. Eng. Chem. Res., 54(25) (2015) 6551-6558.

[25] C. Xu, C. and T. Xie, Review of microfluidic liquid-liquid extractors. Ind. Eng. Chem. Res., 56(27) (2017) 7593-7622.

[26] A. Hibara, M. Fukuyama, M. Chung, C. Priest, M.A. Proskurnin, Interfacial phenomena and fluid control in micro/nanofluidics, Anal Sci. 32(1) (2016)11-21. 
[27] L. Shui, J. C.T. Eijkel, A. van den Berg, Multiphase flow in microfluidic systems - Control and applications of droplets and interfaces, Adv. Colloid and Interface Sci. 133(1) (2007) 35-49.

[28] C.-X.Zhao, A.P.J. Middelberg, Two-phase microfluidic flows, Chem. Eng. Sci. 66(7) (2011) 1394-1411.

[29] T. Minagawa, M. Tokeshi, T. Kitamori, Integration of a wet analysis system on a glass chip: determination of Co(ii) as 2-nitroso-1-naphthol chelates by solvent extraction and thermal lens microscopy, Lab Chip. 1(1) (2001) 72-75.

[30] E. Kolar, R.P.R.Catthoor, F.H. Kriel, R. Sedev, S. Middlemas, E. Klier, G. Hatch, C. Priest Microfluidic solvent extraction of rare earth elements from a mixed oxide concentrate leach solution using Cyanex® 572, Chem. Eng. Sci. 148 (2016) 212-218.

[31] G; Hellé, C. Mariet, G. Cote, Liquid-liquid extraction of uranium(VI) with Aliquat(R) 336 from $\mathrm{HCl}$ media in microfluidic devices: Combination of micro-unit operations and online ICP-MS determination, Talanta 139 (2015) 123-131.

[32] M. Tokeshi, T. Minagawa, K. Uchiyama, A. Hibara, K. Sato, H. Hisamoto, T. Kitamori, Continuous-flow chemical processing on a microchip by combining microunit operations and a multiphase flow network, Anal. Chem. 74 (7) (2002) 1565-1571.

[33] T. Maruyama, H. Matsushita, J. Uchida, F. Kubota, N. Kamiya, M. Goto, Liquid membrane operations in a microfluidic device for selective separation of metal ions, Anal. Chem. 76(15) (2004) 4495-4500.

[34] M. Tokeshi, T. Minagawa, T. Kitamori, Integration of a microextraction system on a glass chip: ion-pair solvent extraction of Fe(II) with 4,7-Diphenyl-1,10-phenanthrolinedisulfonic acid and trin-octylmethylammonium chloride, Anal. Chem. 72 (7) (2000) 1711-1714.

[35] H. Bruus, Theoretical microfluidics. Edition Oxford University Press (2008).

[36] T. Cubaud, D. Henderson, X. Hu, Separation of highly viscous fluid threads in branching microchannels, Microfluid. Nanofluid. (2016). DOI 10.1007/s10404-016-1720-7

[37] H. Hotokezaka, M. Tokeshi, M. Harada, T. Kitamori Y. Ikeda, Development of the innovative nuclide separation system for high-level radioactive waste using microchannel chip-extraction behavior of metal ions from aqueous phase to organic phase in microchannel, Prog. Nuc. Energ. 47(1-4) (2005) 439-447.

[38] J. Zhang, Z. Qin, D. Deng, J. Liao, X. Wei, N. Zhang, A novel method for the online measurement of impurities in uranium by coupling microfluidics with ICP-MS J. Anal. At. Spectrom. 2016 31(2016) 934-939. 
[39] J. Zhang, J. S. Liao, D. C. Deng, H. S. Wang, Z. L. Chen, Solvent extraction of uranium by laminar flow in microfluidic chips, Adv. Materials Res. 709 (2013) 485-490.

[40] J.-P. Jasmin, A. Vansteene, T. Vercouter, C. Mariet A simple and adaptive methodology to use commercial microsystem as screening tool: Validation with the U-TBP chemical system, Solv.Extr. Ion Exch 35 (2017) 1-13.

[41] G. Hellé, C. Mariet, G. Cote, Liquid-liquid microflow patterns and mass transfer of radionuclides in the systems $\mathrm{Eu}(\mathrm{III}) / \mathrm{HNO}_{3} / \mathrm{DMDBTDMA}$ and $\mathrm{U}(\mathrm{VI}) / \mathrm{HCl} /$ Aliquat ${ }^{\circledR}$ 336. Microfluid. Nanofluid. 17(6) (2014) 1113-1128.

[42] G. Hellé, S. Roberston, S. Cavadias, C. Mariet, G. Cote, Towards numerical prototyping of labson-chip: modeling for liquid - liquid microfluidic devices for radionuclides extraction, Microfluid. Nanofluid. 19(5) (2015) 1245-1257.

[43] Y. Ban, Y. Kikutani, M. Tokeshi, Y. Morita, Extraction of Am(III) at the interface of organicaqueous two-layer flow in a microchannel, J. Nucl. Sci. Technol. 48(10) (2011) 1313-1318.

[44] M. Yamamoto, S. Taguchi, S. Sato, N. Surugaya, Evaluation of plutonium(IV) extraction rate between nitric acid and tri-n-butylphosphate solution using a glass chip microchannel, J Sep Sci. 8(10) (2015) 1807-1812.

[45] M. Tokeshi, T. Kitamori, Continuous flow chemical processing on a microchip using operations and a multiphase flow network. Prog. Nucl. Energ., 2005. 47(1-4) (2005) 434-438.

[46] T. Thorsen, S.J. Maerkl, S.R. Quake, Microfluidic large-scale integration. Science, 298(5593) (2002) 580-584.

[47] Malengier B, Pushpavanam S, D'haeyer S (2011) Optimizing performance of liquid-liquid extraction in stratified flow in micro-channels. J. Micromech. Microeng. 21(11): 115030

[48] A.-L. Dessimoz, L. Cavin, A. Renken, L. Kiwi-Minsker, Liquid-liquid two-phase flow patterns and mass transfer characteristics in rectangular glass microreactors, Chem. Eng. Sci. 63(16) (2008) 4035-4044.

[49] P. R Danesi and R. Chiarizia,, The kinetics of metal solvent extraction. Crit. Rev. Anal. Chem. 1980, 10(1980) 1, 1-126.

[50] G.A. Yagodin and V.V. Tarasov, Interfacial phenomena in solvent extraction. Solvent Extr. Ion Exch. 1984, 2(2) (1984) 139-178.

[51] Lewis, J. B. The Mechanism of Mass Transfer of Solutes across Liquid-liquid Interfaces - Part I: The Determination of Individual Transfer Coefficients for Binary Systems. Chem. Eng. Sci. 3(6) (1924) 248 
[52] Nitsch, W.; Hillekamp, K. Zur Kinetic der Zinkionenextraktion aus Wasser in dithizonbeladene solventien. Chem-Ztg 96(5) (1972) 254-261.

[53] Albery, W. J.; Burke, J. F.; E.B., L.; Hadgraft, J. Interfacial transfer studied with a rotating diffusion cell. J. Chem. Soc. 72 (1975) 1618-1626.

[54] W. Nitsch, Die Behandlung der stoffübertragung zwischen flüssigen Phasen als problem der grenzflächenreaktionen. Ber. Dtsch. Bot. Ges. 69, 9/10 (1965) 884-893.

[55] K.P. Nichols, R.R. Pompano, L. Li, A.V. Gelis, R.F. Ismagilov, Toward mechanistic understanding of nuclear reprocessing chemistries by quantifying lanthanide solvent extraction kinetics via microfluidics with constant interfacial area and rapid mixing, J Am Chem Soc. 133(39) (2011) 15721-15729.

[56] A. Vansteene A., J.-P.Jasmin, G. Cote, C. Mariet, Segmented micro-flows as a tool for optimization of mass transfer in liquid-liquid extraction: application at the extraction of europium (III) by a malonamide, Ind. Eng. Chem. Res. 57 (2018) 11572-115828.

[57] . H. Xu, S. W. Li, J. Tan, G. S. Luo, Correlations of droplet formation in T-junction microfluidic devices: from squeezing to dripping, J Microfluid Nanofluid 5 (2008) 711-717.

[58] T. Cubaud, B. M. Jose, S.Darvishi, R. Su, Droplet breakup and viscosity-stratified flows in microchannels, Int. J. Multiphase Flow 39 (2012) 29-33.

[59] A. Vansteene A., J.-P.Jasmin, S. Cavadias, C. Mariet, G. Cote, Towards chip prototyping: A model for droplet formation at both $\mathrm{T}$ and $\mathrm{X}$-junctions in dripping regime, Microfluid. Naanofluid., 22(6) (2018) 61-75.

[60] J. R. Burns and C. Ramshaw, The intensification of rapid reactions in multiphase systems using slug flow in capillaries, Lab on a Chip 1 (2001) 10-15.

[61] A. Ufer, M. Mendorf, A. Ghaini, D.W. Agar, Liquid-liquid slug flow capillary microreactor, Chem. Eng. Technol. 34(3) (2011) 353-360.

[62] M. Wegener, N. Paul, M. Kraume, Fluid dynamics and mass transfer at single droplets in liquid/liquid systems, Inter. J. Heat Mass Transfer 71 (2014) 475-495.

[63] D. Tsaoulidis, P. Angeli; Effect of channel size on mass transfer during liquid-liquid plug flow in small scale extractors, Chem. Eng. J. 262 (2015) 785-793.

[64] H. Song, J.D. Tice, R.F. Ismagilov, A microfluidic system for controlling reaction networks in time Angew. Chem. Int. Ed. 2003, 42, 767] 
[65] D. Tsaoulidis V. Dore, P. Angeli, N.V. Plechkova, K.R. Seddon, Extraction of dioxouranium(VI) in small channels using ionic liquids, Chem. Eng. Res. Des. 91(4) (2013) 681-687.

[66] D. Tsaoulidis V. Dore, P. Angeli, N.V. Plechkova, K.R. Seddon, Dioxouranium(VI) extraction in microchannels using ionic liquids, Chem. Eng. J. 227 (2013) 151-157.

[67] M. Darekar, K.K. Singh, S. Mukhopadhyay, K.T. Shenoy, S.K. Ghosh, Solvent extraction in microbore tubes with UNPS-TBP in dodecane system, Sep. Purif. Technol. 128 (2014) 96-105.

[68] S. Nirvik, M. Darekar, K.K. Singh, S. Mukhopadhyay, K.T. Shenoy, S.K. Ghosh, Solvent extraction and stripping studies in microchannels with TBP nitric acid system Solv. Extr. Ion Exch. 32(3) (2014) 281-300.

[69] E. P. Horwitz, D. C Kalina, H. Diamond, G. F. Vandegrift, W. W. Schulz (1985) The TRUEX process - a process for the extraction of the transuranic elements from nitric acid wastes utilizing modified PUREX solvent, Solv. Extr. Ion Exch. 3(1-2) (1985) 75-109.

[70] M. Nemer, C. Roberts, L. Hughes, N. Wyatt, C. Brooks, R. Rao, Drop mass transfer in a microfluidic chip compared to a centrifugal contactor, AiCHE Journal 60(8) (2014) 3071-3078.

[71] Q. Li, P. Angeli, Intensified Eu(III) extraction using ionic liquids in small channels, Chem. Engi. Sci. 143 (2016) 276-286.

[72] L. Zhang, F. Xie, S. Li, S. Yin, J. Peng, S. Ju Solvent extraction of Nd(III) in a Y type microchannel with 2-ethylhexyl phosphoric acid-2-ethylhexyl ester, Green Process Synth 4 (2015) 3-10.

[73] S. Nishihama, Y. Tajiri, K. Yoshizuka, Separation of lanthanides using micro solvent extraction system, Ars Separatoria Acta 4 (2006) 18-26.

[74] K. Ooe, Y. Tashiro, D. Saika, Y. Kitamoto, K. Matsuo, T. Takabe, T. Kuribayashi, N. Takahashi, T. Yoshimura, W. Sato, K. Takahisa, A. Shinohara, Development of on-line solvent extraction system with microchips for heavy element chemistry, J. Nucl. Rad. Chem. Sci. 8(2) (2007) 59-62.

[75] C. A. Launiere and A. V. Gelis, High precision droplet-based microfluidic determination of americium(III) and lanthanide(III) kinetics solvent extraction separation, Ind. Eng. Chem. Res. 55 (2016) 2272-2276.

[76] M. N. Kashid, L. Kiwi-Minsker, Microstructured reactors for multiphase reactions: State of the art Ind. Eng. Chem. Res. 48 (2009) 6465-6485.

[77] D.M. Fries, T. Voitl, P.R. von Rohr, Liquid extraction of vanillin in rectangular microreactors, Chem. Eng. Technol. 31(8) (2008) 1182-1187. 
[78] E.P. Horwitz, M.L. Dietz, R. Chiarizia, H. Diamond, A.M. Essling, D. Graczyk, Separation and preconcentration of uranium from acidic media by extraction chromatography, Anal. Chim. Acta 266 (1992) 25-37.

[79] J.R. FitzPatrick, B.S. Schake, J. Murphy, K. Holmes, M.H. West, The removal of uranium from acidic media using ion exchange and/or extraction chromatography, in: R.G. Bautista (Ed.) Emerging Separation Technologies for Metals II 1996, pp. 119-134.

[80] E.P. Horwitz, M.L. Dietz, R. Chiarizia, H. Diamond, S.L. Maxwell Iii, M.R. Nelson, Separation and preconcentration of actinides by extraction chromatography using a supported liquid anion exchanger: application to the characterization of high-level nuclear waste solutions, Anal. Chim. Acta 310 (1995) 63-78.

[81] R. Chiarizia, E.P. Horwitz, Radiolytic stability of some recently developed ion exchange and extraction chromatographic resins containing diphosphonic acid groups, Solv. Extr. Ion Exch. (2000) 18(1) 109-132.

[82] E. P. Horwitz, D. R. McAlister, A. H. Bond, R. E. Barrans Jr, Novel extraction of chromatographic resins based on tetraalkyldiglycolamides: characterization and potential applications, Solv. Extr. Ion Exch. (2005) 23(3) 319-344.

[83] G. Marinov, A. Marinova, M. Milanova, S. Happel, N. A. Lebedev, Abigail Drokhlyansky, Nijat Mirzayev, D. V. Karaivanov \& D. V. Filosofov, Sorption of rare-earth elements and Ac on UTEVA resin in different acid solutions, Solv. Extr. Ion Exch. (2017) 35(4) 280-291.

[84] M. Losno, I. Ferrante, R. Brennetot, J. Varlet, B. Grenut, E. Amblard, S. Descroix, C. Mariet, Photochemical synthesis and versatile functionalization method of a robust porous poly(ethylene glycol methacrylate-co-allyl methacrylate) monolith dedicated to radiochemical separation in a centrifugal microfluidic platform, Micromachines, 7(6) (2016) 45-57.

[85] M. Losno, J. Pellé, M. Marie, I. Ferrante, R. Brennetot, S. Descroix, C. Mariet, Separation and preconcentration of actinides from concentrated nitric acid by extraction chromatography in microsystems, Talanta, 185 (2018) 586-591.

[86] H. Yin, K. Killeen, R. Brennen, D. Sobek, M. Werlich, T. van de Goor, Microfluidic chip for peptide analysis with an integrated HPLC column, sample enrichment column, and nanoelectrospray tip, Anal. Chem. 77 (2005) 527-533.

[87] H. Yin, K. Killeen, The fundamental aspects and applications of Agilent HPLC-Chip, J. Sep. Sci. 30 (2007) 1427-1434.

[88] N. Hebert, D.W. Neyer, J.B. Young, R. van Soest, Using $200 \mu \mathrm{m}$ ID cHiPLC columns for increased sample throughput in peptide quantitation, J. Biomol. Tech. 22 (Suppl) (2011) S58. 
[89] J. Gao, B.T. Manard, A. Castro, D.P. Montoya, N. Xu, R.M. Chamberlin, Solid-phase extraction microfluidic devices for matrix removal in trace element assay of actinide materials, Talanta 167 (2017) 8-13.

[90] G. Guiochon, Monolithic columns in high-performance liquid chromatography, J. Chromatogr. A 1168 (2007) 101-168.

[91] F. Svec, C.G. Huber, Monolithic materials: promises, challenges, achievements, Anal. Chem. 78 (2006) 2100-2107.

[92] F. Svec, Less common applications of monoliths: preconcentration and solid phase extraction, J. Chromatogr. B Anal. Technol. Biomed. Life Sci. 841 (2006) 52-64.

[93] O.G. Potter, E.F. Hilder, Porous polymer monoliths for extraction: diverse applications and platforms, J. Sep. Sci. 31 (2008) 1881-1906.

[94] A. Namera, A. Nakamoto, T. Saito, S. Miyazaki, Monolith as a new sample preparation material: recent devices and applications, J. Sep. Sci. 34 (2011), 901-924.

[95] J.C. Masini, F. Svec, Porous monoliths for on-line sample preparation: A review, Anal. Chim. Acta 964 (2017) 24-44.

[96] J.P. Lafleur and E.D. Salin, Pre-concentration of trace metals on centrifugal microfluidic discs with direct determination by laser ablation inductively coupled plasma mass spectrometry, J. Anal. At. Spectrom. 24 (2009) 1511-1516.

[97] M. Yamaura, H. Matsuda, Sequential separation of actinides and lanthanides by extraction chromatography using a CMPO-TBP/XAD7 column, J. Radioanal. Nucl. Chem. 241 (1999) 277280.

[98] G. M. Whitesides, What comes next?, Lab Chip11 (2011) 191-193. 